\title{
EL JUS COGENS, ¿SALIÓ DEL GARAJE?
}

\author{
Carlos EsPaliú Berdud
}

Profesor Agregado de Derecho Internacional Público y de Derecho de la Unión Europea Director del Institut Carlemany d'Estudis Europeus Universitat Internacional de Catalunya

SUMARIO: 1 . INTRODUCCIÓN.-2. LA PRÁCTICA CONVENCIONAL.-3. LA PRÁCTICA DE LA ASAMBLEA GENERAL Y DEL CONSEJO DE SEGURIDAD DE LAS NACIONES UNIDAS.-3.1. La Asamblea General.-3.2. El Consejo de Seguridad.-4. LA PRÁCTICA DE OTROS ÓRGANOS Y ORGANISMOS INTERNACIONALES.-4.1. La Comisión de Derecho internacional.-4.2. Otros organismos internacionales.-5. LA PRÁCTICA DE LAS DIVERSAS JURISDICCIONES INTERNACIONALES.-5.1. La Corte Internacional de Justicia.-5.2. Otras jurisdicciones internacionales.-6. LA PRÁCTICA ESTATAL.-7. CONCLUSIONES.

\section{INTRODUCCIÓN}

La noción de normas imperativas o de jus cogens en el Derecho internacional hunde sus raíces en categorías jurídicas muy ancianas, retomadas en un debate doctrinal de los años del periodo de entreguerras del siglo pasado. Es probable que el espaldarazo definitivo se lo dieran autores como Alfred Verdross y Sir Hersch Lauterpacht, ambos en su doble perfil de profesores de gran renombre y, posteriormente, de miembros de la Comisión de Derecho Internacional (CDI) ${ }^{1}$.

\footnotetext{
1 Así lo afirma, en relación con Verdross, Karl Zemanek [véase ZEMANEK, K., «The Metamorphosis of "jus cogens": from an Institution of Treaty Law to the Bedrock of the International Order?» en CANNIZZARo, E. (ed.), The Law of Treaties beyond the Vienna Convention, Oxford, Oxford University Press, 2011 , p. 382] y se deja entrever en un artículo publicado en 1966 por el propio Verdross (VERDROss, A., «Jus Dispositivus and Jus Cogens in International Law», AJIL, vol. 60, 1966, núm. 1, p. 55).
} 
Aunque la génesis de la noción se encuentre, sin ningún género de dudas, en la doctrina, su impulso proviene de la corriente humanizadora que marcó el Derecho internacional tras la Segunda Guerra Mundial. En cualquier caso, es evidente que aparece en la superficie del Derecho positivo codificado ${ }^{2}$ en la Convención de Viena sobre Derecho de los Tratados de 1969 (CVDT), amparada en un amplio consenso entre los Estados, al menos en cuanto a la necesidad de proteger determinadas normas consideradas esenciales por la comunidad de Estados, de las arbitrariedades que algunos de ellos quisieran plasmar en acuerdos de voluntad. De esta forma, se llegó a definir a la normas imperativas en el art. 53 como aquellas que son aceptadas y reconocidas por la comunidad internacional de Estados en su conjunto como normas que no admiten acuerdo en contrario y que sólo pueden ser modificadas por normas ulteriores de Derecho internacional general que tengan el mismo carácter.

Menos claro resultó el consenso acerca del régimen jurídico que debía arropar a las normas de jus cogens, pero acabó imponiéndose uno centrado en el establecimiento de la nulidad de los tratados contrarios a las normas imperativas y en la producción de otros efectos derivados de esa nulidad. En efecto, en virtud de los arts. 53 y 64, cualquier tratado que en el momento de su celebración, o posteriormente, contravenga una norma imperativa de Derecho internacional general será nulo. Asimismo, se establece que dicha nulidad tendrá como consecuencia la imposición a las partes en el tratado nulo, no sólo de la obligación de eliminar en lo posible las consecuencias de todo acto ejecutado conforme al tratado, lo que constituye la consecuencia normal de la nulidad por cualquier otra causa, sino también la de ajustar sus relaciones mutuas a la norma de jus cogens (art. 71). Junto a ello, se prevé que no se admitirá en caso de nulidad de un tratado por contravención de una norma de jus cogens la división de las disposiciones del tratado (art. 44). Finalmente, se establece en su art. 66, cosa no revolucionaria pero bastante extraordinaria, que las controversias que se susciten entre los Estados en relación con la interpretación y aplicación de los arts. 53 y 64 serán sometidas de modo obligatorio a la Corte Internacional de Justicia.

Como se puede apreciar, la adopción del régimen jurídico de las normas imperativas deja abierta una serie de interrogantes - en particular en cuanto a la naturaleza y la determinación de las mismas-que no recibieron respuesta en su día. De hecho, cuando la CDI presentó su proyecto de artículos a la Conferencia de Viena de 1968-1969 advirtió, en relación con la definición del jus cogens contenida en lo que luego llegaría a constituir el art. 53 de la

2 La CDI en sus comentario al art. 50 del proyecto de artículos presentados a la Conferencia de Viena de 1968-1969 ya advirtió que: "The emergence of rules having the character of jus cogens is comparatively recent, [...]», véase United Nations Conference on the Law of Treaties, Documents of the Conference, (A/CONF.39/11/Add.2), p. 67, párr. 3. Véase también en este sentido, SuY, E., "Commentaire de l’article 53 de la Convention de Vienne sur le droit des traités de 1969», en CorTEN, O. y KLEIN, P. (eds.), Les Conventions de Vienne sur le droit des traités. Commentaire article par article, vol. II, Bruselas, Université Libre de Bruxelles, Bruylant, 2006, p. 1906. 
CVDT, que, desde su punto de vista, el mejor modo de proceder era limitarse en ese momento a establecer en términos generales que un tratado es nulo si entra en conflicto con una norma de jus cogens y dejar que la práctica estatal y la jurisprudencia de los tribunales internacionales determinara el contenido completo de esa regla ${ }^{3}$.

Entiendo que tras más de cuarenta años desde la adopción de la Convención de Viena ha transcurrido ya un tiempo prudencial como para poder seguir el consejo de la Comisión, teniendo una buena perspectiva de la evolución del ordenamiento jurídico. De esta forma, nos proponemos examinar la práctica subsiguiente a la adopción de la CVDT, con el fin de extraer conclusiones fundadas sobre la vigencia de la noción y de la institución del jus cogens, así como de su alcance, en el Derecho internacional contemporáneo.

Hemos de advertir, no obstante, que no nos limitaremos a la práctica estatal y la jurisprudencia de los tribunales internacionales, como apuntaba la CDI, sino que, desde el punto de vista subjetivo, bucearemos en toda la práctica internacional, incluyendo la de las organizaciones internacionales. Asimismo, desde el punto de vista objetivo, resultará del máximo interés no limitarse sólo a la práctica convencional, sino tratar de ampliar el ámbito de búsqueda, pues entendemos que a partir de la Convención de Viena de 1969, cualquier acto o norma que sea contrario a una norma de jus cogens, con independencia de su naturaleza o de la entidad de la que provenga, también será nulo ${ }^{4}$. De hecho, como lo afirma la CDI, la práctica internacional parece venir a validar este enfoque, pues «[...] diversos tribunales, tanto nacionales como internacionales, han afirmado la idea de las normas imperativas en contextos que no se limitan a la validez de los tratados» ${ }^{5}$. Además, la propia CDI, como veremos ulteriormente con detenimiento, advirtió en 2006, en un documento sobre los actos unilaterales de los Estados, que era nula toda de-

3 "The Commission considered the right course to be to provide in general terms that a treaty is void if it conflicts with a rule of jus cogens and to leave the full content of this rule to be worked out in State practice and in the jurisprudence of international tribunals", véase United Nations Conference on the Law of Treaties, Doc. (A/CONF.39/11/Add.2), op. cit., nota 2, p. 67, párr. 3.

${ }^{4} \mathrm{Al}$ incluirse disposiciones paralelas en la Convención de Viena de 1986 sobre el Derecho de los tratados celebrados entre Estados y organizaciones internacionales y entre organizaciones internacionales entre sí, es evidente que los actos nulos pueden emanar de una organización internacional. El Profesor Robert Kolb afirma, en esta dirección, que la noción de jus cogens provoca que no sólo sean nulos los tratados, sino toda norma jurídica (véase KoLB, R., «Observation sur l'évolution du concept de jus cogens», RGDIP, vol. 113, 2009, núm. 4, p. 844).

5 Véase Informe de la Comisión de Derecho internacional - 53. ${ }^{\circ}$ periodo de sesiones (23 de abril a 1 de junio y 2 de julio a 10 de agosto de 2001), Asamblea General, Documentos Oficiales, $56 .^{\circ}$ periodo de sesiones, Suplemento núm. 10 (A/56/10), p. 216. Es el sentido, en mi opinión, además, del art. 26 del proyecto de artículos de la CDI sobre responsabilidad internacional de los Estados, de 2001, que establece que ninguna disposición del capítulo donde se exponen las causas de exclusión de la ilicitud «[...] excluirá la ilicitud de cualquier hecho de un Estado que no esté en conformidad con una obligación que emana de una norma imperativa de Derecho internacional general». En su explicación del texto de este artículo la CDI afirmó que, «[c]uando existe una oposición aparente entre obligaciones primarias, una de las cuales se deriva para un Estado directamente de una norma imperativa de Derecho internacional general, es evidente que esa obligación imperativa prevalecerá» (véase ibid., p. 215). 
claración unilateral que estuviera en oposición con una norma imperativa de Derecho internacional general ${ }^{6}$.

La auscultación de la práctica para observar la salud del jus cogens reviste particular relevancia dado el alcance teórico de estas normas. Se debería poder descartar que precisamente las normas denominadas imperativas no vengan a ser más que una especie de soft law. Situación tremendamente contradictoria, que haría perder al Derecho internacional gran parte de su credibilidad, ya de por sí contestada por muchos ${ }^{7}$. Desde luego, se han registrado bastantes voces alzadas en contra de esta institución ${ }^{8}$, si bien es cierto que en los últimos años ese concierto parece que va disminuyendo en volumen, al menos en cuanto al propio concepto se refiere ${ }^{9}$.

No obstante, antes de pasar a analizar la práctica estimamos pertinente matizar, en cuanto a la naturaleza de las normas imperativas reflejada en la CVDT, que un examen literal de la noción de esta institución, que acabó incluyéndose en el art. 53 de la CVDT, induce a la constatación de que los legisladores se aseguraron de que figurara exclusivamente un elemento material o positivo, tendente a la exigencia de un consenso de la comunidad de Estados en su conjunto para la determinación de las normas que pasarían a integrar este selecto club. Este elemento material o positivo fue introducido para garantizar la seguridad jurídica necesaria en tan trascendente operación ${ }^{10}$. Sin embargo, un estudio de los trabajos preparatorios de la CVDT y

6 Informe de la Comisión de Derecho internacional de su 58. periodo de sesiones (de 1 de mayo a 9 de junio y 3 de julio a 11 de agosto de 2006), Asamblea General, Documentos Oficiales, $61 .^{\circ}$ periodo de sesiones, Suplemento núm. 10 (A/61/10), p. 419.

7 Véase sobre este punto: Truyol y Serra, A., «Théorie du droit international public. Cours général», RCADI, vol. 173, 1981, pp. 104 y ss.

8 Si se quiere profundizar en los argumentos de los negadores del jus cogens, véase KolB, R., Théorie du jus cogens international. Essai de relecture du concept, París, Presses Universitaires de France, 2001, pp. 33-58.

9 El Profesor Caplan advierte en este sentido que: «While the existence of jus cogens in International Law is an increasingly accepted proposition, its exact scope and content remains an open question» (véase CAPLAN, L. M., "State Immunity, Human Rights and "jus cogens": a Critique of the Normative Hierarchy Theory», AJIL, vol. 97, 2003, p. 742). Asimismo, véase CASSESE, A., "For an Enhanced Role of jus Cogens», en Cassese, A., (ed.), Realizing Utopia. The Future of International Law, Oxford, Oxford University Press, 2012, p. 163.

10 Recuérdese que el texto propuesto ab initio por la CDI para la Conferencia de Viena, que situaba las normas de jus cogens entre las de Derecho internacional general, no sufrió importantes modificaciones durante la misma. Tan sólo llegó a buen puerto una enmienda de calado, la que patrocinaron conjuntamente España, Finlandia y Grecia, para que se insertasen las palabras «reconocida por la comunidad internacional como una norma» entre las palabras «Derecho internacional general» $\mathrm{y}$ "que no admita acuerdo en contrario» del texto propuesto por la CDI [véase United Nations Conference on the Law of Treaties, Documents of the Conference (A/CONF.39/C.1/L.306 and Add.1 and 2)]. Esta enmienda, introducida hacia el fin de la primera sesión de la Conferencia de Viena [United Nations Conference on the Law of Treaties, Documents of the Conference (A/CONF.39/11), p. 471, párrs. 2-7], pretendía hacer frente a las objeciones elevadas por varias delegaciones al texto propuesto en el proyecto de la CDI al estimar demasiado evanescente la referencia al Derecho internacional general como cuerpo donde se encuentran las normas imperativas (ibid., p. 316, párr. 7). El delegado de Grecia abundó en la idea anterior a la hora de la presentación de la enmienda, advirtiendo que si el elemento esencial del jus cogens internacional radicaba en la universalidad de su aceptación por la comunidad internacional, era mejor explicitarlo en el texto mismo del artículo. Añadiendo, además, que las normas de esa naturaleza 
de las raíces históricas ${ }^{11}$ de estas normas superiores permite apreciar como, de modo implícito, en la noción de jus cogens coexiste también un elemento espiritual consistente en la protección de los valores esenciales de la comunidad internacional, y que estaría detrás de esa eventual iniciativa comunitaria para señalar ciertas normas como superiores e imperativas.

Finalizaremos esta introducción recordando que el Prof. Brownlie sostuvo en su día que el jus cogens era un vehículo que salía raramente del garaje. Por tanto, en definitiva, se puede afirmar que nuestra misión consiste, en última instancia, en comprobar si ha salido y, si lo hubiera hecho, en averiguar a dónde ha ido ${ }^{12}$.

\section{LA PRÁCTICA CONVENCIONAL}

En relación con los tratados internacionales, salvo la excepción de la Convención de Viena de 1986 sobre el Derecho de los tratados celebrados entre Estados y organizaciones internacionales y entre organizaciones internacionales entre sí, ningún otro tratado ha incluido en su articulado referencia alguna al jus cogens o las normas imperativas.

En cuanto a la aceptación de la CVDT, hay que hacer notar que el art. 66 es, de largo, aquél sobre el que más reservas se han formulado ${ }^{13}$. Sobre los otros artículos relativos a disposiciones que versan sobre el jus cogens apenas se han efectuado ${ }^{14}$. La Convención de Viena de 1986 contiene cuatro artículos prácticamente idénticos a los arts. 44, 53, 64 y 71 de la Convención de 1969. Estas disposiciones reunieron un gran consenso entre los miembros de la CDI y apenas fueron objeto de observaciones específicas por parte de los Estados y de las organizaciones internacionales durante la discusión en el seno del órgano codificador ${ }^{15}$. En cuanto al art. 66 en la Convención de

\footnotetext{
debían ser aceptadas por la conciencia jurídica de la comunidad de Estados como constitutivas de un orden público internacional (ibid., p. 295, párr. 20).

11 Sobre este extremo véase, entre otros, Gómez Robledo, A., «Le jus cogens international: sa genèse, sa nature, ses fonctions», $R C A D I$, vol. 172, 1981, núm. III, pp. 17-68; KoLB, R., op. cit., nota 8 , pp. 197-198.

12 En sus palabras: "I think jus cogens has become part of lex lata. At the same time, as has been pointed out, the vehicle does not often leave the garage. In other words the concept does not seem to have a lot of obvious relevance». Brownlie, I., "Comment», en CASSESE, A. y WeILER, J. H. H. (eds.), Change and Stability in International Law-Making, Berlín, Walter de Gruyter \& Co., 1988, p. 110.

13 En la actualidad están vigentes las reservas de Alemania, Arabia Saudita, Armenia, Argelia, Belarus, Bélgica, Brasil, Canadá, China, Cuba, Dinamarca (hace una reserva en relación con la Parte V de la CVDT y el art. 66), Finlandia (también hace una reserva en relación con la Parte V de la CVDT y el art. 66), Guatemala, Reino Unido, Rusia, Tanzania (también hace una reserva en relación con la Parte V de la CVDT y el art. 66), Túnez, Ucrania y Vietnam. Además, Nueva Zelanda, Países Bajos y Portugal han emitido declaraciones sobre esta disposición. Véase al respecto: https://treaties.un.org/pages/ ViewDetailsIII.asp $x$ ? \&src=TREATY\&mtdsg_no=XXIII 1\&chapter=23\&Temp=mtdsg3\&lang=en .

14 Bélgica tiene una reserva vigente en relación con los arts. 53 y 64 (ibid.).

15 Véase, en relación con el art. 44, el Anuario de la Comisión de Derecho internacional 1982, vol. I, p. 136, párr. 6; acerca del art. 53: ibid., p. 152, párr. 28; sobre el art. 64: ibid., p. 161, párr. 41; en fin, en lo concerniente al art. 71: ibid., p. 171, párr. 50 .
} 
1986, destinado a resolver las controversias derivadas de la nulidad, retirada, suspensión y terminación de un tratado, necesariamente tenía que haber diferencias con el texto de 1969, causadas por el hecho de que conforme al Estatuto de la Corte Internacional de Justicia las organizaciones internacionales no poseen ius standi en su jurisdicción contenciosa. Para sortear ese escollo, durante la discusión del proyecto de artículos se avanzaron diversas propuestas complejas, lo que trajo consigo necesariamente un menor consenso entre los miembros de la CDI ${ }^{16}$. Además, durante la Conferencia, fue la disposición que suscitó un mayor debate ${ }^{17}$, siendo finalmente adoptada por una mayoría de 47 a favor, por 23 en contra y 21 abstenciones ${ }^{18}$. En efecto, a la postre se dio por buena una enmienda al texto inicial de la CDI esponsorizada por ocho Estados ${ }^{19}$ que habilitara la posibilidad de que si la Organización de las Naciones Unidas u otra organización internacional autorizada para ello fueran parte en la controversia, se solicitaran opiniones consultivas a la Corte Internacional de Justicia de conformidad con el art. 65 de su Estatuto.

Con posterioridad, se han efectuado pocas reservas y declaraciones acerca de las disposiciones de la Convención de Viena de 1986, que todavía no ha entrado en vigor, y todas las que están vigentes a día de hoy, y se refieren a las normas de jus cogens, se centran en el art. $66^{20}$.

Pero aún más relieve que la escasa inclusión de referencias a las normas de jus cogens en los tratados posteriores a la CVDT reviste el hecho de que, hasta el momento, ningún tratado haya sido declarado nulo en aplicación del régimen previsto en la Convención, o al margen de ella, por violación de una norma imperativa ${ }^{21}$.

No pudiendo ofrecer más que esta escasa práctica reciente y posterior a la CVDT $^{22}$, y aunque se trate de un caso anterior a la Convención de Viena de

\footnotetext{
16 A este respecto, por ejemplo, véase ibid., pp. 283-286.

17 Necesitó de cinco sesiones de la Comisión Plenaria [véase Official Records of the United Nations Conference on the Law of Treaties between States and International Organizations or between International Organizations, Document A/CONF.129/16/Add.l (vol. II), p. 76] y una sesión Plenaria, la séptima, celebrada el 20 de marzo de 1986 [véase Official Records of the United Nations Conference on the Law of Treaties between States and International Organizations or between International Organizations, Document A/CONF.129/16 (vol. I), pp. 25-29].

18 Ibid., p. 27.

19 Austria, Colombia, Irlanda, Japón, México, Nigeria, Países Bajos y Suiza (véase Official Records of the United Nations Conference on the Law of Treaties between States and International Organizations or between International Organizations, Document A/CONF.29/C.l/L.69/Rev.2).

20 Mantienen reservas en relación con el art. 66 Bélgica y Dinamarca. Alemania y los Países Bajos han efectuado declaraciones sobre esta disposición. Por su parte, Senegal, es autor de una declaración de este tenor: "In signing this Convention, [the Government of Senegal declares] that the completion of this formality shall not be interpreted in so far as Senegal is concerned as a recognition of the right of international organizations to appear as parties before the International Court of Justice». Véase, a este respecto: https://treaties.un.org/pages/ViewDetails.aspx?src=TREATY\&mtdsg_no=XXIII-3\&chapter=23\&lang=en.

21 En este sentido, véase CASSESE, A., op. cit., nota 9, p. 159.

22 Sin llegar a tratarse de una determinación de una norma de jus cogens, cobra especial relevancia, no obstante, el ejemplo de protección de una norma que se nos brinda con el párr. 6 del art. 311 de la Convención de Naciones Unidas sobre el Derecho del mar de 1982. Esta disposición se lee así: «Los Estados partes convienen en que no podrán hacerse enmiendas al principio básico relativo al
} 
1969, conviene citar el Acta de la Conferencia de Bruselas de 1890 relativa a la trata de esclavos; ejemplo que fue traído a colación por la propia CDI en sus comentarios de artículos para la preparación de la Conferencia de Viena de 1968-196923. En efecto, en el art. 96 de aquel instrumento se preveía la abrogación de toda estipulación contraria que se pudiera encontrar en las convenciones concluidas entre las Potencias Firmantes ${ }^{24}$.

Para acabar este apartado, y aunque no se trate estrictamente de supuestos de aplicación del régimen del jus cogens, sí que cabe mencionar que algunas disposiciones de los instrumentos fundamentales del Derecho humanitario recuerdan bastante al régimen jurídico previsto en la CVDT para las normas imperativas.

Nos referimos, por ejemplo, al artículo común a los cuatro Convenios de Ginebra de $1949^{25}$ que establece que los acuerdos por los cuales los Estados trataran de restringir los derechos de las personas protegidas por los convenios no producirán efectos ${ }^{26}$. No estamos sin duda, insisto, ante el escenario previsto para la nulidad de los tratados en la CVDT, pero dada la universal aceptación de los cuatro Convenios de Ginebra, se puede decir que mediante este artículo común se ha establecido, de hecho y sin nombrarlo - entre otras cosas porque los Convenios de Ginebra preceden en veinte años a la CVDT-, un régimen por el que se elevan determinadas normas a un status superior que las protege contra todo acuerdo en contrario ${ }^{27}$.

Nos referimos, asimismo, a las disposiciones del párr. 2 del art. 1 del Protocolo I de $1977^{28}$, que dispone que:

«En los casos no previstos en el presente Protocolo o en otros acuerdos internacionales, las personas civiles y los combatientes quedan bajo la protección y el

patrimonio común de la humanidad establecido en el art. 136 y en que no serán partes en ningún acuerdo contrario a ese principio». Se puede apreciar cómo el legislador va aquí más allá de una simple prohibición de derogación de una norma posterior. De hecho, como lo resalta Lauri Hannikainen, los trabajos preparatorios de la Convención dejan ver algunos intentos dirigidos a que se declarara norma imperativa el principio por el cual se consagra la Zona y sus recursos como patrimonio común de la humanidad [véase HanniKainen, L., Peremptory Norms (Jus Cogens) in International Law. Historical Development, Criteria, Present Status, Helsinki, Finnish Lawyers' Publishing Company, 1988, pp. 567-572].

${ }^{23}$ United Nations Conference on the Law of Treaties..., Doc. (A/CONF.39/11/Add.2), op. cit., nota 2, p. 81, párr. 1

${ }_{24}$ General Act of the Brussels Conference relating to the African Slave Trade, CTS 1890, vol. 173, p. 188.

25 6/6/6/7.

${ }^{26}$ Véase, a este respecto, Meron, T., «The Geneva Conventions and Public International Law. British Foreign and Commonwealth Office Conference commemorating the 60th Anniversary of the 1949 Geneva Conventions, London, 9 July 2009», International Review of the Red Cross, vol. 91, 2009, núm. 875 , p. 624 .

27 En el artículo común 7/7/7/8, también se prohíbe la renuncia por parte de las personas protegidas de los derechos que los convenios les reconocen. Sobre el régimen del jus cogens y el estatuto de los prisioneros de guerra en el Derecho humanitario, véanse ScHMAHL, S., «An Example of Jus Cogens: The Status of Prisoners of War», en Tomuschat, C. y Thouvenin, J. M. (eds.), The Fundamental Rules of the International Legal Order: Jus cogens and Obligations Erga omnes, Dordrecht, Martinus Nijhoff, 2006, pp. 41-68, y WECKEL, Ph., «Un exemple remarquable d'application du jus cogens, le statut de prisonnier de guerre», ibid., pp. 69-82.

28 Protocolo del 8 de junio de 1977 adicional a los Convenios de Ginebra del 12 de agosto de 1949 relativo a la protección de las víctimas de los conflictos armados internacionales (Protocolo I). 
imperio de los principios del derecho de gentes derivados de los usos establecidos, de los principios de humanidad y de los dictados de la conciencia pública».

Es conocido que este texto es una materialización contemporánea de la cláusula Martens, incluida por decisión unánime en el preámbulo de las Convenciones de La Haya de 1899 y 1907 relativas a las leyes y costumbres de la guerra terrestre ${ }^{29}$. Estamos, más allá de toda duda razonable, ante un supuesto de reconocimiento convencional de que determinados principios esenciales del Derecho humanitario son inderogables, con independencia de que hayan sido codificados en tal o cual tratado o de que los actores en cualquier conflicto armado real que pueda producirse hayan prestado su consentimiento en obligarse por esos instrumentos jurídicos.

¿No recuerda esta disposición a lo que afirmó la Corte Internacional de Justicia en su opinión consultiva, de 8 de julio de 1996, en el asunto de la Legalidad de la amenaza o el empleo de armas nucleares, cuando se refería a que las normas esenciales de los Convenios de La Haya y de Ginebra de Derecho humanitario deben ser observadas por todos los Estados, hayan o no ratificado aquellos acuerdos, "because they constitute intransgressible principles of international customary law» ${ }^{30}$ ? ¿No vendría también la disposición citada del Protocolo I a reforzar las opiniones que vertimos anteriormente a favor de la importancia del elemento espiritual en el jus cogens?

\section{LA PRÁCTICA DE LA ASAMBLEA GENERAL Y DEL CONSEJO DE SEGURIDAD DE LAS NACIONES UNIDAS}

\subsection{La Asamblea General}

La práctica de la Asamblea General testimonia una progresiva permeabilización de la institución y del régimen jurídico del jus cogens. En efecto, durante varias décadas la Asamblea General nunca mencionó expresamente a este tipo de normas, y mucho menos se preocupó de determinar alguna de ellas. Sin embargo, sí que se podía apreciar una utilización parcial, en algunas de sus resoluciones, del régimen jurídico de la nulidad de los tratados o actos contrarios a las normas imperativas. Así, en el contexto de la problemática existente en el Oriente Medio, la Asamblea General ha ido adoptando numerosas resoluciones invocando unas normas o principios superiores y proclamando la nulidad de los actos que los infringían. Por ejemplo, en su Resolución 34/65 B ${ }^{31}$, de 29 de noviembre de 1979, la Asamblea condenó con

${ }^{29}$ Véase a este respecto el comentario al párr. 2 del art. 1 del Protocolo en el sitio Internet del Comité Internacional de la Cruz Roja, en http://www.icrc.org/applic/ihl/ihl.nsf/Comment.xsp?viewCommen $t s=$ LookUpCOMART\&articleUNID=6C86520D7EFAD527C12563CD0051D63C.

${ }^{30}$ Legality of the Threat or Use of Nuclear Weapons, Advisory Opinion, ICJ Reports 1996, pár. 79, p. 257.

31 Resolución adoptada por 75 votos a favor, por 33 en contra, con 37 abstenciones (75-33-37). Las indicaciones del voto de las siguientes resoluciones que citaremos a continuación en las notas seguirán este mismo sistema. 
determinación todos los acuerdos y tratados que constituyeran una violación flagrante de los derechos del pueblo palestino, los principios de la Carta y las resoluciones aprobadas en los diversos foros internacionales. Pero lo que es más importante, se declaró que los acuerdos de Camp David carecían de validez por cuanto pretendían determinar el futuro del pueblo palestino y de los territorios ocupados por Israel desde $1967^{32}$. En otras resoluciones se declaraba que todas las medidas y decisiones adoptadas por Israel, la Potencia ocupante, en violación de las disposiciones pertinentes del Convenio de Ginebra relativo a la protección de personas civiles en tiempos de guerra, de 12 de agosto de 1949, y en contravención de las resoluciones pertinentes del Consejo de Seguridad, eran ilegales y carecían de validez ${ }^{33}$. Finalmente, mediante una larga serie de resoluciones, comenzando por la $37 / 123 \mathrm{~A}^{34}$, la Asamblea General, reafirmando el principio fundamental según el cual la adquisición de territorio por la fuerza es inadmisible, declaraba que la decisión de Israel, de 14 de diciembre de 1981, de imponer sus leyes, su jurisdicción y su administración en el territorio sirio ocupado de los Alto del Golán y en Jerusalén - constituyendo un acto de agresión con arreglo a su Resolución 3314 (XXIX) - era nula ${ }^{35}$.

Si nos fijamos en los guarismos con los que han sido adoptadas estas resoluciones, se observará que casi siempre han sido pocos los Estados que han votado en contra, aunque a veces hayan sido muy numerosos los Estados que se han abstenido. En cualquier caso, en general se aprecia un apoyo cada vez más sólido a este tipo de resoluciones.

Una acogida todavía más clara del régimen jurídico de la nulidad de los tratados, que se opongan a una norma imperativa por parte de la Asamblea General, la encontramos en la Resolución 42/22, de 18 de noviembre de 1987, adoptada por consenso, mediante la que se aprobó la «Declaración sobre el mejoramiento de la eficacia del principio de abstención de la amenaza o de la utilización de la fuerza en las relaciones internacionales». En este texto se declara solemnemente que: «[...] 2. El principio de abstenerse de recurrir a la

32 Otras Resoluciones en esta línea son: la 36/120 F (88-21-36), la 39/146 A (100-16-28), la 40/168 A (98-19-31), la 41/162 A (104-19-32), la 42/209 B (99-19-33), la 43/54 A (103-18-30), la 44/40 A (109-18$31)$, la 45/83 A (99-19-32) o la 46/82 A (93-37-27).

33 Por ejemplo las Resoluciones 56/62 (145-4-2), 57/127 (148-6-6), 58/99 (150-6-19), 59/124 (1497-22), 60/107 (148-7-17), 61/119 (157-9-14), 62/109 (156-7-11), 63/98 (165-8-4), 64/94 (162-9-5), 65/105 (165-9-2), 66/79 (159-9-4) y 67/11 (164-8-6).

34 87-22-31.

35 En relación con la cuestión de los Altos del Golán y de Jerusalén, véanse las Resoluciones 38/180 C (137-1-3), 47/63 A (73-3-70), 48/59 A (141-1-11) y B (65-2-83), 49/87 A (138-2-7) y B (77-2-70), 50/22 A (133-1-13) y B (66-2-79), $51 / 27$ (148-1-13), 51/28 (84-2-71), 52/53 (148-1-9), 52/54 (92-2-65), 53/37 (149-1-7), 53/38 (97-2-58), 54/37 (139-1-3), 54/38 (92-2-53), 55/50 (145-1-5), 55/51 (96-2-55), 55/134 (150-1-4), 56/63 (147-2-3), 57/128 (155-1-9), 58/100 (163-1-11), ES-10/14 (90-8-74), 59/32 (155-7-15), $59 / 33$ (111-6-60), 59/125 (160-2-15), 60/40 (106-6-62), 60/41 (153-7-12), 60/108 (156-1-15), $61 / 26$ (1576-10), 61/27 (107-6-60), 61/120 (163-2-16), 62/84 (160-6-7), 62/85 (111-6-56), 62/110 (164-1-10), 63/30 (163-6-6), 63/31 (116-6-52), 63/99 (171-1-7), 64/20 (163-7-5), 64/21 (116-7-51), 64/95 (166-1-11), 65/17 (166-6-4), 65/18 (118-7-52), 65/106 (167-1-9 ), 66/18 (164-7-5), 66/19 (119-7-53), 66/80 (162-1-11), 67/24 (162-7-6), 67/25 (110-6-59) y 67/122 (168-1-11). 
amenaza o al uso de la fuerza en las relaciones internacionales es universal en su carácter y es obligatorio para todos los Estados [...]». Como se puede fácilmente colegir, esta afirmación es muy cercana a lo que sería una determinación de una norma de jus cogens. Pero, además, la Asamblea añade que: «11. Es nulo todo tratado cuya celebración se haya obtenido por la amenaza o el uso de la fuerza en violación de los principios de Derecho internacional incorporados en la Carta». Estamos ante una transposición o asunción del art. 52 de la CVDT, que declara la nulidad de los tratados cuya celebración se haya obtenido mediante la amenaza o el uso de la fuerza; artículo que muy bien puede tratarse de una especificación de una norma de jus cogens.

Sin embargo, aún más determinante que lo anterior es el tratamiento que la Asamblea reserva a la norma que prohíbe la tortura; tratamiento que se puede considerar muy cercano a una determinación expresa de una norma imperativa. En efecto, en una serie de resoluciones recientes, a partir de la 59/182 ${ }^{36}$, la Asamblea ha señalado:

«Recordando que el derecho a no ser sometido a torturas y otros tratos o penas crueles, inhumanos o degradantes no admite excepción y debe estar protegido en todas las circunstancias, incluso en tiempos de disturbios internos o internacionales o de conflicto armado, y que todos los instrumentos internacionales en la materia afirman expresamente la prohibición de la tortura.

Recordando también que algunos tribunales internacionales, regionales y nacionales, entre ellos el Tribunal Internacional para el enjuiciamiento de los presuntos responsables de las violaciones graves del Derecho internacional humanitario cometidas en el territorio de la ex Yugoslavia desde 1991, han reconocido que la prohibición de la tortura es una norma imperante del Derecho internacional» $[\ldots]^{37}$.

Adviértase cómo, por boca de la Asamblea, en una resolución adoptada por consenso, se afirma que el derecho a no ser sometido a tortura no admite excepción de ningún tipo, es universal y aplicable en toda circunstancia, incluyendo disturbios y conflictos armados internacionales o internos. ¿ No sería legítimo inferir que ello equivale a emplear, sin nombrarlas, los rasgos de las normas imperativas? Además, por si fuera poco, en el segundo de los párrafos que hemos destacado, la Asamblea, si bien no afirma por sí misma que la prohibición de la tortura es una norma imperativa, sí lo pone en boca de algunos tribunales internacionales, iy lo recuerda!

Por último, debemos exponer que, en materia de responsabilidad internacional, la Asamblea, en relación con los proyectos de artículos preparados por la CDI, tanto sobre responsabilidad del Estado por hechos

36 Con anterioridad, las resoluciones anuales de este tipo, hasta la Resolución 58/164, no afirmaban que la prohibición de la tortura es una norma imperativa.

37 Estas fórmulas se repiten en las Resoluciones sucesivas: 60/148, 63/166, 64/153, 65/205, 66/150 y 67/101. Nótese que la expresión «norma imperante» es una mala traducción, pues la versión inglesa utiliza la expresión "peremptory norm of international law» y la versión francesa «norme impérative». De hecho, en la Resolución similar 63/166, de 19 de febrero de 2009, ya se emplea la expresión «norma imperativa». 
internacionalmente ilícitos ${ }^{38}$, como acerca de la responsabilidad de las organizaciones internacionales ${ }^{39}$, ha adoptado por consenso resoluciones por las cuales se tomaba nota de los artículos presentados por la CDI y los señalaba a la atención de los Estados. A efectos de nuestro análisis, trataremos estos proyectos en sede de la práctica del órgano codificador del Derecho internacional.

\subsection{El Consejo de Seguridad}

El Consejo de Seguridad, en ejercicio de su responsabilidad primordial en el mantenimiento de la paz y la seguridad internacionales, que la Carta de las Naciones Unidas le atribuye, ha adoptado varías resoluciones declarando nulos ciertos actos por considerarlos contrarios a determinados principios. En efecto, en el contexto de la situación en el Oriente Medio, mediante su Resolución 252 (1968), de 21 de mayo, después de sostener que la adquisición de territorio mediante la conquista militar es inadmisible, estimaba que todas las medidas de carácter legislativo y administrativo tomadas por Israel y los actos que había ejecutado, incluso la expropiación de tierras y bienes, que tendían a modificar el estatuto jurídico de Jerusalén, eran nulos y no podían modificar aquel estatuto ${ }^{40}$. Esta misma condena se repitió, ante la continuación de la ocupación por Israel, en las Resoluciones 267 (1969), de 3 de julio ${ }^{41}, 476$ (1980), de 30 de junio $^{42}, 478$ (1980), de 20 de agosto $^{43}$. Por la Resolución 497 (1981), de 17 de diciembre, se censura con la nulidad la decisión de Israel de imponer sus leyes, su jurisdicción y su administración en el territorio ocupado de los Altos del Golán ${ }^{44}$. Por sus Resoluciones 452 (1979), de 20 de julio $^{45}$, y 465 (1980), de 1 de marzo ${ }^{46}$, el Consejo de Seguridad indica que la política de asentamientos en los territorios árabes ocupados desde 1967 no tenía validez jurídica.

Del mismo modo, con ocasión de la invasión de Kuwait por Iraq, el Consejo de Seguridad tuvo ocasión de declarar en varias ocasiones la nulidad de la anexión. Así, en su Resolución 662 (1990), de 9 de agosto de 1990, adoptada por unanimidad, declaraba que la anexión de Kuwait por parte de Iraq debía de «considerarse nula y sin valor». Afirmación que reiteró en sus

\footnotetext{
38 Resolución 56/83, de 12 de diciembre de 2001.

39 Resolución 66/100, de 27 de febrero de 2012.

40 Resolución adoptada por 13 votos a favor, ninguno en contra y dos abstenciones. A continuación se seguirá el mismo sistema que empleamos para referirnos a los resultados de las votaciones en la Asamblea General.

${ }^{41}$ Adoptada por unanimidad.

42 (14-0-1).

43 (14-0-1).

44 Adoptada por unanimidad.

45 (14-0-1).

46 Adoptada por unanimidad. Asimismo, se declaran sin validez la medidas adoptadas por Israel para modificar el carácter físico, la composición demográfica, la estructura institucional, etc., de los territorios árabes ocupados.
} 
Resoluciones 664 (1990) de 18 de agosto, igualmente adoptada por unanimidad, y 670 (1990), de 25 de septiembre, adoptada por 14 votos a favor por uno en contra.

\section{LA PRÁCTICA DE OTROS ÓRGANOS Y ORGANISMOS INTERNACIONALES}

\subsection{La Comisión de Derecho internacional}

La CDI ha jugado un papel primordial a la hora de trasladar la institución del jus cogens de la doctrina al Derecho internacional positivo, como se evidencia mediante la historia legislativa de las Convenciones de Viena sobre Derecho de los tratados de 1969 y 1986. Pero lejos de quedarse ahí, la CDI ha vuelto a utilizar la noción de normas imperativas, y previsto un régimen particular para ellas, en algún otro proyecto de artículos u otros textos que ha preparado por encargo de la Asamblea General de las Naciones Unidas.

En efecto, en primer lugar, la CDI elaboró un proyecto de artículos sobre la responsabilidad del Estado por hechos internacionalmente ilícitos que fue señalada a la atención de los Estados por la Asamblea General de las Naciones Unidas en su Resolución 56/83, de 12 de diciembre de 2001 ${ }^{47}$. En su capítulo III de la Segunda Parte, se prevé un régimen agravado de la responsabilidad de los Estados para el caso de las violaciones graves de obligaciones emanadas de normas imperativas del Derecho internacional general (arts. 40 y 41). Junto a ello, se dispone en el art. 26 que ninguna circunstancia podrá excluir la ilicitud de un acto contrario a una norma imperativa. Finalmente, se establece que las contramedidas no podrán afectar, ni a la obligación de abstenerse de recurrir a la amenaza o al uso de la fuerza, ni a las obligaciones establecidas para la protección de los derechos humanos fundamentales, ni a las obligaciones de carácter humanitario que prohíben las represalias, ni a «[o]tras obligaciones que emanan de normas imperativas del Derecho internacional general» (art. 50).

Además, se encuentra en el proyecto una disposición relativa a la invocación de la responsabilidad por un Estado distinto del Estado lesionado (art. 48), cuando la titularidad de la obligación violada recaiga en la comunidad internacional en su conjunto (art. 48.1); permitiéndose entonces que cualquier Estado pueda reclamar al Estado responsable la cesación del hecho ilícito, seguridades y garantías de no repetición, así como el cumplimiento de

\footnotetext{
47 Véase A/RES/56/83. Sobre la evolución del proyecto de artículos en el seno de la CDI, véase Pérez Giralda, A., "El proyecto de la Comisión de Derecho internacional sobre responsabilidad de los Estados, al final del camino", REEI, 2002, núm. 4. Véase, también, sobre los artículos relativos a las normas imperativas: CEBADA ROMERO, A., "Los conceptos de obligación erga omnes, ius cogens y violación grave a la luz del nuevo proyecto de la CDI sobre responsabilidad de los Estados por hechos ilícitos», REEI, 2002, núm. 4, pp. 10-14.
} 
la obligación de reparar (art. 48.2). Esta distinción en cuanto a la capacidad de reaccionar frente a la violación, en atención a la naturaleza de la obligación violada, constituye un reflejo de la estela marcada en el Derecho internacional por la Corte Internacional de Justicia en virtud de su decisión de 1970, en el asunto de la Barcelona Traction, al afirmar la existencia de obligaciones erga omnes ${ }^{48}$; institución que guarda una innegable conexión con la de las normas imperativas, como ha sido puesto de manifiesto reiteradamente por la doctrina ${ }^{49}$.

En segundo lugar, en el proyecto de artículos sobre la responsabilidad de las organizaciones internacionales que la CDI presentó a la consideración de la Asamblea General de las Naciones Unidas y del que ésta tomó nota en su Resolución 66/100, de 27 de febrero de $2012^{50}$, se incluyen también disposiciones relativas a las normas imperativas. En esencia, hay que hacer notar que constituyen, mutatis mutandi, disposiciones simétricas a las incluidas en el proyecto sobre responsabilidad de los Estados ${ }^{51}$; al igual que acontece, prácticamente, con el resto del proyecto ${ }^{52}$.

En relación con los dos proyectos de artículos sobre responsabilidad internacional mencionados, la estrategia de la CDI en atención a su futura positivación fue la misma, a saber, recomendar a la Asamblea General que tomara nota del proyecto de artículos en una resolución e incluyera dicho texto como anexo de la resolución, y esperar a que la Asamblea estudiara, más adelante, la posibilidad de elaborar una convención basada en el proyecto de artículos.

48 Barcelona Traction, Light and Power Company, Limited, arrêt, CIJ Recueil 1970, p. 33, párrs. 33-34.

49 Véanse, entre otros, Acosta Estévez, J. B., "Normas de ius cogens, efecto erga omnes, crimen internacional y la teoría de los círculos concéntricos», Anuario de Derecho Internacional, vol. XI, 1995, pp. 3-22; Cebada Romero, A., op. cit., nota 47; Picone, P., Comunità internazionale e obblighi "erga omnes", Nápoles, Jovene, 2006; VILlalPando, S., L'émergence de la communauté internationale dans la responsabilité des Etats, París, Presses Universitaires de France, 2005.

50 Véase A/RES/66/100.

51 En el art. 26 se establece que no existe ninguna circunstancia excluyente de la responsabilidad por violación de una norma imperativa. En los arts. 25, 33, 43 y 49 se prevé un régimen jurídico particular para las violaciones de obligaciones cuya titularidad corresponde a la comunidad de Estados en su conjunto. Se incluye, sobre todo, en el Capítulo III de la Parte Tercera (violaciones graves de obligaciones emanadas de normas imperativas de Derecho internacional general), arts. 41 y 42, un régimen agravado de la responsabilidad de las organizaciones internacionales. De esta forma, se dispone que los Estados y las organizaciones internacionales cooperarán para poner fin, por medios lícitos, a toda violación grave de tales normas y que ningún Estado y ninguna organización internacional reconocerá como lícita una situación creada por una violación grave de tales normas, ni prestará ayuda o asistencia para mantener esa situación. Finalmente, en el art. 53, se señalan determinadas obligaciones que no pueden ser afectadas por las contramedidas, como la prohibición de recurrir al uso o la amenaza de la fuerza, las establecidas para la protección de los derechos humanos, las obligaciones de carácter humanitario que prohíben las represalias u otras obligaciones que emanen de normas imperativas de Derecho internacional general.

52 Sobre el proyecto de artículos véase BlokkeR, N. y Wessel, R., «Introduction: First Views at the Articles on The Responsibility of International Organizations», International Organizations Law Review, vol. 9, 2012, núm. 1, pp. 1-6; Wouters, J. y ODERMATT, J., «Are All International Organizations Created Equal?», ibid., pp. 7-14; Aspremont, J., "The Articles on the Responsibility of International Organizations: Magnifying the Fissures in the Law of International Responsibility», ibid., pp. 15-29; Amerasinghe, C. F., "Comments on the ILC's Draft Articles on the Responsibility of International Organizations», ibid., pp. 29-31. 
Pero, fuera del ámbito de la responsabilidad, la CDI también se ha ido refiriendo a las normas imperativas al hilo de su trabajo en otras materias. Así, en tercer lugar, podemos mencionar el caso de los actos unilaterales. En el informe sobre la labor realizada en su $48 .^{\circ}$ periodo de sesiones, en 1996, la CDI propuso a la Asamblea General que se incluyera, como tema apropiado para la codificación y el desarrollo progresivo del Derecho internacional, el derecho de los actos unilaterales de los Estados ${ }^{53}$; a lo que la Asamblea General accedió mediante su Resolución 51/160. A tales efectos, se puso en pie un grupo de trabajo que, para 2006, había finalizado su tarea. De ese modo, en agosto de ese año, la Comisión pudo aprobar un conjunto de diez «Principios rectores» - junto con una serie de comentarios a los mismos- aplicables a las declaraciones unilaterales de los Estados capaces de crear obligaciones jurídicas, y señaló dichos Principios rectores a la atención de la Asamblea General ${ }^{54}$. Pues bien, en su Principio rector octavo, la CDI hizo notar que «[es] nula toda declaración unilateral que esté en oposición con una norma imperativa de Derecho internacional general». La Comisión añadió en sus comentarios al mismo que tal regla se inspiraba en la norma análoga enunciada en el art. 53 de la CVDT, pues la mayoría de sus miembros estimaban que nada se oponía a trasponer esa norma al caso de las declaraciones unilaterales ${ }^{55}$.

En cuarto lugar, podemos referirnos al famoso trabajo de la CDI sobre fragmentación del ordenamiento jurídico internacional. Es bien conocido que la CDI decidió en 2002 ocuparse de la cuestión de la jerarquía normativa en el Derecho internacional, el jus cogens, las obligaciones erga omnes y el art. 103 de la Carta de las Naciones Unidas, en el marco de un estudio más amplio sobre la fragmentación del Derecho internacional, para lo que constituyó un grupo de estudio ad hoc presidido por Martti Koskenniemmi. Los trabajos de este grupo de estudio estuvieron finalizados en 2006, por lo que pudo entregar un informe y una serie de conclusiones a la Comisión en ese mismo 58..$^{\circ}$ periodo de sesiones. La CDI tomó nota de esos textos y los presentó a la atención de la Asamblea General en agosto de $2006^{56}$. La CDI, de entrada, resaltó en sus conclusiones que no existe ninguna relación jerárquica entre las principales fuentes de Derecho internacional, tratados, costumbre y principios generales del Derecho, tal como se indica en el art. 38 del Estatuto de la Corte Internacional de Justicia. Pero, al mismo tiempo, advirtió que «[u]na norma de Derecho internacional puede ser superior a otras por la importancia de su contenido y por la aceptación universal de su superioridad. Así ocurre con las normas imperativas de Derecho internacional ${ }^{57}$. Finalmente, acerca del contenido del jus cogens, la Comisión no declaró ro-

53 Véase Asamblea General, Documentos Oficiales, 51. ${ }^{\circ}$ periodo de sesiones, Suplemento núm. 10 (A/51/10), pp. 357-359, párr. 249.

54 Véase Informe de la Comisión de Derecho Internacional de su 58. periodo de sesiones (de 1 de mayo a 9 de junio y 3 de julio a 11 de agosto de 2006), Asamblea General, Documentos Oficiales, 61. ${ }^{\circ}$ periodo de sesiones, Suplemento núm. 10 (A/61/10), p. 405.

55 Ibid., p. 419.

56 Ibid., p. 444.

57 Ibid., p. 461, párrs. 31-32. 
tundamente cuáles son las referidas normas, limitándose a señalar los ejemplos de normas de jus cogens citados con mayor frecuencia. Para el órgano codificador de las Naciones Unidas, entre ellas deben contarse «las que prohíben la agresión, la esclavitud, la trata de esclavos, el genocidio, la discriminación racial, el apartheid y la tortura, así como las normas básicas de Derecho internacional humanitario aplicables en conflictos armados, y el derecho a la libre determinación». No las presentaba como una lista cerrada, sino que admitió que otras normas también podrían tener el carácter de jus cogens "en la medida en que sean aceptadas y reconocidas por la comunidad internacional de Estados en su conjunto como normas que no admiten acuerdo en contrario» ${ }^{58}$.

En quinto lugar, en su reciente Guía de la Práctica sobre las Reservas a los Tratados, aprobado por la Comisión en su 63 . $^{\circ}$ periodo de sesiones ${ }^{59}$, se ha incluido una directriz - la 4.4.3 - titulada Falta de efecto en una norma imperativa de Derecho internacional general (jus cogens), dirigida a reafirmar que una reserva que se formule a una disposición convencional que refleje una norma imperativa estará desprovista de todo efecto en cuanto a la aplicación de esa norma ${ }^{60}$. Con esta aclaración se desarrolla el alcance de las normas imperativas en materia de Derecho de los tratados, pues si según la CVDT los tratados que se opongan a estas normas serán nulos, cuanto más es inaceptable que las reservas a ciertas disposiciones de un tratado que posean rango de imperatividad puedan desplegar efectos ${ }^{61}$. En buena lógica esta aclaración no era estrictamente necesaria, pero debe ser bien acogida pues explicita un efecto propio de esta categoría normativa.

En suma, como se puede apreciar en todos estos textos, la CDI va marcando la trayectoria de una futura penetración y expansión de la institución de las normas imperativas en el ordenamiento jurídico internacional, incluso más allá del Derecho de los tratados. En efecto, en sus documentos sobre los actos unilaterales y sobre la jerarquía normativa en el Derecho internacional, la CDI extrae conclusiones muy acertadas, desde mi punto de vista, sobre la relevancia que tiene en nuestro ordenamiento la existencia de tal tipo de normas. Así es, ya que la Comisión estima que si un tratado deviene nulo por su oposición con una norma de jus cogens, con igual razón lo hará otro tipo de fuente jurídica, en el caso en cuestión un acto unilateral del Estado. Asimismo, con su texto sobre la jerarquía en el Derecho internacional, la CDI no hace sino manifestar el gran alcance que posee en este ordenamiento el hecho de que haya una categoría de normas, consideradas como imperativas - las que son aceptadas como tales por la comunidad de Estados en su conjunto o las que poseen un contenido particularmente relevante-, lo que

58 Ibid., p. 462, párr. 33.

59 Véase Documento A/66/10/Add. 1

60 Ibid., Comentario a la directriz 4.4.3, párr. 2.

61 En este sentido, véase también Kadelbach, S., «Jus Cogens, Obligations Erga Omnes and other Rules-The Identification of Fundamental Norms», en Tomuschat, C. y Thouvenin, J. M. (eds.), op. cit., nota 27, p. 29. 
las eleva sobre el resto de normas con independencia de su naturaleza convencional, consuetudinaria o de otro tipo.

Junto a ello, con la inclusión en sus proyectos de artículos sobre responsabilidad internacional, tanto de los Estados como de las organizaciones internacionales, de varias disposiciones relativas a las normas imperativas, la CDI demuestra ir proyectando las consecuencias de la existencia de normas primarias de jus cogens hacia el marco jurídico de las normas secundarias.

\subsection{Otros organismos internacionales}

En cuanto a los órganos de protección de los derechos humanos basados en la Carta de las Naciones Unidas, tanto la antigua Comisión de Derechos Humanos ${ }^{62}$, como hoy el Consejo de Derechos Humanos de las Naciones Unidas, al abordar la situación del pueblo palestino, han utilizado repetidamente en sus resoluciones el concepto de normas de jus cogens y han sostenido que el principio a la libre determinación de los pueblos constituye una de esa normas ${ }^{63}$.

Asimismo, acerca de la práctica de los órganos de protección de los derechos humanos basados en tratados, también cabe hacer mención de ciertos hitos importantes. Por su parte, el Comité contra la tortura ha calificado en repetidas ocasiones que la prohibición de la tortura ha adquirido el rango de norma de jus cogens en el Derecho internacional contemporáneo ${ }^{64}$. Por ejemplo, en una de sus recomendaciones a España advirtió, en relación con la aplicación de la Ley de Amnistía de 1977, que, «[...] en consideración al arraigado reconocimiento del carácter de jus cogens de la prohibición de la tortura, el enjuiciamiento de actos de tortura no se debe limitar por el principio de legalidad, ni por el efecto de la prescripción ${ }^{65}$.

Del mismo modo, el Comité de Derechos Humanos, en su opinión general núm. 24, de 4 de noviembre de 1994, en su reflexión sobre la posibilidad de emitir reservas a determinados artículos del Pacto Internacional de Derechos Civiles y Políticos o a sus Protocolos Facultativos, la negó en relación con aquellos artículos del Pacto que recogían "peremptory norms». Al mismo tiempo, puso de manifiesto que las normas que prohíben la tortura y la privación arbitraria de la vida constituyen ejemplos de normas imperativas; negando así, por tanto, entre otras cosas, que los artículos (Part I).

${ }^{62}$ Véase, por ejemplo, la Resolución 2005/1, Documento E/2005/23 (Part I), E/CN.4/2005/134

63 Véase, por ejemplo, la Resolución 26/27, de 22 de marzo de 2013, Documento A/HRC/RES/22/27.

${ }^{6}$ Informe del Comité contra la Tortura, 39. periodo de sesiones (5 a 23 de noviembre de 2007) $40 .^{\circ}$ periodo de sesiones (28 de abril a 16 de mayo de 2008), Documento A/63/44, Observación General núm. 2, Anexo VI.

${ }^{65}$ Informe del Comité contra la Tortura. $43 .^{\circ}$ periodo de sesiones (2 a 20 de noviembre de 2009) 44. ${ }^{\circ}$ periodo de sesiones (26 de abril a 14 de mayo de 2010), Documento A/65/44, punto 55, España, párr. 21, pp. 60-61. 
que las contienen en los instrumentos en cuestión pudieran ser objeto de reservas ${ }^{66}$.

Finalmente, debemos hacer notar que, al margen de estos actos de alta relevancia jurídica, en el marco del trabajo de estos órganos y organismos de protección de los derechos humanos se han elaborado numerosos informes oficiales en los que con frecuencia aparecen referencias a las normas de jus cogens y se señalan alguna de ellas ${ }^{67}$.

\section{LA PRÁCTICA DE LAS DIVERSAS JURISDICCIONES INTERNACIONALES}

\subsection{La Corte Internacional de Justicia}

En cuanto a la Corte Internacional de Justicia, debe destacarse que durante mucho tiempo, probablemente demasiado, este tribunal nunca había afirmado la existencia de las normas de jus cogens, y cuando barajaba el concepto lo hacía indirectamente, exponiendo la posición de alguna de las partes ${ }^{68}$. Con ello, se daba pie a pensar, incluso, que se procuraba evitar la utilización de la expresión investigada. Como es lógico, durante décadas, la Corte tampoco había individualizado ninguna de esas normas.

Pero, si sorprendente era el hecho de que el órgano judicial principal de las Naciones Unidas no se hubiera jamás referido a las normas imperativas, aún más lo ha sido el que se haya referido a ellas, y señalado una en concreto, la que prohíbe el genocidio, jen una sentencia sobre competencia y admisibilidad! En efecto, de forma inesperada, en su Sentencia de 3 de febrero de 2006, sobre la competencia y admisibilidad de la nueva demanda del Congo contra Ruanda en el asunto de las Actividades armadas sobre el territorio del Congo, la Corte reiteró su jurisprudencia en lo tocante a que la naturaleza de las normas relativas al fondo de una controversia no influía en la esfera

\footnotetext{
${ }^{66}$ General Comment No. 24: Issues relating to reservations made upon ratification or accession to the Covenant or the Optional Protocols thereto, or in relation to declarations under article 41 of the Covenant: 04/11/1994, Document CCPR/C/21/Rev.1/Add.6, General Comment No. 24 (General Comments).

67 Véase, por ejemplo, entre otros, el Informe conjunto de los relatores especiales sobre los derechos económicos, sociales y culturales. Los derechos civiles y políticos. Situación de los detenidos en la bahía de Guantánamo, Documento E/CN.4/2006/120; Report of the Special Rapporteur (of the Human Rights Council) on the promotion and protection of human rights and fundamental freedoms while countering terrorism, Martin Scheinin, Documento A/HRC/10/3; el Informe del Relator Especial del Consejo de Derechos Humanos sobre la tortura y otros tratos o penas crueles, inhumanos o degradantes, Juan E. Méndez, Documento A/HRC/22/53; el Estudio temático de la Oficina del Alto Comisionado de las Naciones Unidas para los Derechos Humanos sobre el efecto de las medidas coercitivas unilaterales en el disfrute de los derechos humanos, con recomendaciones sobre los medios de poner fin a esas medidas, Documento A/HRC/19/33; el Informe de la comisión de investigación internacional independiente nombrada por el Consejo de Derechos Humanos sobre la situación en la República Árabe Siria, Documento A/HRC/S-17/2/ Add.1, etcétera.

68 En este sentido, véase también Hannikainen, L., op. cit., nota 22, pp. 192-194; CzAPLANSKI, W., "Concept of jus cogens and Obligations erga omnes in International Law in the light of Recent Developments», Polish Yearbook of International Law, 1997-1998, pp. 88-91.
} 
de la competencia; aunque en esta ocasión mencionando también expresamente a la normas de jus cogens. Para la Corte, el hecho de que una norma posea tal carácter, como es probablemente el caso de la prohibición del genocidio, "[...] ne saurait en lui-même fonder la compétence de la Cour pour en connaître. En vertu du Statut de la Cour, cette compétence est toujours fondée sur le consentement des parties» ${ }^{69}$.

Con posterioridad ya la Corte se ha referido con mayor frecuencia al jus cogens, y con mayor claridad, como es el caso de su opinión consultiva sobre la Conformidad con el Derecho internacional de la declaración unilateral de independencia de Kosovo ${ }^{70}$, o de la reciente sentencia en el asunto de las Inmunidades jurisdiccionales del Estado (Alemania c. Italia: Grecia interviniente), donde llega a definir a este tipo de normas como aquellas que no pueden ser derogadas ${ }^{71}$. No obstante, aquí la Corte quiso volver a reiterar y precisar que si bien las reglas que determinan el alcance y la extensión de la jurisdicción, así como las condiciones en las que esa jurisdicción puede ser ejercida, no derogan las reglas de naturaleza material que tengan rango de jus cogens, tampoco hay nada intrínseco a la noción de jus cogens que imponga la modificación o la no aplicación de aquellas reglas jurisdiccionales ${ }^{72}$.

Esta concepción la aplica la Corte no sólo a su propia competencia, sino también a las reglas relativas a las inmunidades jurisdiccionales de los altos cargos de los Estados acusados de crímenes internacionales en los tribunales internos de terceros Estados, pues recordando su sentencia en el asunto de la Orden de detención, ha advertido que, en aquel asunto, sin mencionar expresamente la noción de jus cogens, ella juzgó entonces que el hecho de que un ministro de Asuntos Exteriores estuviera acusado de crímenes contrarios a normas que tienen indudablemente valor de jus cogens, no impedía a la República Democrática del Congo solicitar que el interesado se beneficiara de la inmunidad, de conformidad con el Derecho internacional consuetudinario ${ }^{73}$.

El último paso en esta dirección viene constituido por el dado en el párr. 99 de su Sentencia de 4 de julio de 2012, en el asunto de las Cuestiones concernientes a la obligación de perseguir o extraditar, cuando la Corte vuelve a señalar una norma de este tipo, ahora la que prohíbe la tortura. En efecto, en palabras de la Corte, "[...] l'interdiction de la torture relève du droit internatio-

69 Activités armées sur le territoire du Congo (nouvelle requête: 2002) (République démocratique du Congo c. Rwanda), compétence et recevabilité, arrêt, CIJ Recueil 2006, p. 32, párr. 64. Asimismo, en el párr. 125 de la sentencia, la Corte vuelve a insistir. En sus propias palabras: "La Cour estime enfin nécessaire de rappeler que le seul fait que des droits et obligations erga omnes ou des règles impératives du droit international général (jus cogens) seraient en cause dans un différend ne saurait constituer en soi une exception au principe selon lequel sa compétence repose toujours sur le consentement des parties (voir paragraphe 64 ci-dessus)» (ibid., p. 52, párr. 125).

70 Accordance with international law of the unilateral declaration of independence in respect of Kosovo, Advisory Opinion of 22 July 2010, párr. 81.

${ }^{71}$ Immunités juridictionnelles de l'Etat (Allemagne c. Italie); Grèce (intervenant), arrêt, CIJ Recueil 2012, párr. 95.

72 Ibid.

73 Ibid. 
nal coutumier et elle a acquis le caractère de norme impérative (jus cogens)» ${ }^{74}$. La Corte sustenta su afirmación haciendo notar: que esta prohibición reposa sobre una práctica internacional extendida y sobre la opinio iuris de los Estados; que figura en numerosos instrumentos internacionales con vocación de universalidad; que ha sido introducida en el Derecho interno de la casi totalidad de los Estados; y que los actos de tortura son denunciados regularmente en el seno de instancias nacionales e internacionales ${ }^{75}$.

\subsection{Otras jurisdicciones internacionales}

Por otro lado, podemos constatar cómo, por su parte, otras jurisdicciones internacionales - la Corte Interamericana de Derechos Humanos, el Tribunal Penal Internacional para la ex Yugoslavia, el Tribunal Penal Internacional para Ruanda, el Tribunal Europeo de Derechos Humanos y el Tribunal de Justicia de la Unión Europea- han empezado a referirse a este tipo de normas, y a señalar algunas de ellas.

Cabría destacar el hecho de que la primera jurisdicción internacional que empleó el concepto de jus cogens y aplicó el régimen contenido en el art. 64 de la Convención de Viena de 1969 fue la Corte Interamericana de Derechos Humanos. Así, en su Sentencia de 10 de septiembre de 1993, en el caso Aloeboetoe y otros, Reparaciones (Art. 63.1. Convención Americana sobre Derechos Humanos), ese tribunal alegó, entre otras muchas cosas, que el Tratado de 1762, al regular el comercio de esclavos, «hoy sería nulo por ser contrario a reglas de jus cogens superveniens ${ }^{76}$. Posteriormente, este tribunal ha empleado la expresión en numerosos asuntos y ha sostenido que han alcanzado este rango las normas que prohíben la tortura ${ }^{77} \mathrm{u}$ otros tratamientos crueles, inhumanos y degradantes ${ }^{78}$; el principio fundamental de equidad y no discriminación ${ }^{79}$, así como el principio del acceso a la justicia ${ }^{80}$.

Por su parte la Comisión Interamericana de Derechos Humanos ha utilizado frecuentemente el concepto de normas de jus cogens y ha llegado a

${ }^{74}$ Questions concernant l'obligation de poursuivre ou d'extrader (Belgique c. Sénégal), arrêt, CIJ Recueil 2012, párr. 99.

75 Ibid.

76 Corte Interamericana de Derechos Humanos, caso Aloeboetoe y otros, Sentencia de 10 de septiembre de 1993 (Reparaciones y costas), Serie C, núm. 15, párr. 57.

77 Corte Interamericana de Derechos Humanos, caso de los Hermanos Gómez Paquiyauri v. Perú, Sentencia de 8 de julio de 2004 (Fondo, Reparaciones y Costas), Serie C, núm. 110, párr. 112.

78 Corte Interamericana de Derechos Humanos, caso Caesar v. Trinidad y Tobago, Sentencia de 11 de marzo de 2005 (Fondo, Reparaciones y Costas), Serie C, núm. 123, párr. 18.

79 Corte Interamericana de Derechos Humanos, Condición Jurídica y Derechos de los Migrantes Indocumentados, Opinión Consultiva OC-18/03, de 17 de septiembre de 2003, Serie A, núm. 18, párr. 101.

${ }^{80}$ Corte Interamericana de Derechos Humanos, caso Goiburú y otros v. Paraguay, Sentencia de 22 de septiembre de 2006 (Fondo, Reparaciones y Costas), Serie C, núm. 153, párr. 131. Sobre la jurisprudencia de la Corte Interamericana en materia de jus cogens, véase CANÇAdo Trindade, A. A., "Some Reflections on the Reassuring Expansion of the Material Content of jus cogens», en VENTURINE, G. y BARIATti, S. (eds.), Diritti Individuali e Giustizia Internazionale, Liber Fausto Pocar, vol. 1, Milán, Giufrè, 2009, pp. 65-79. 
identificar algunas de ellas, como el derecho a la vida ${ }^{81}$, la prohibición de la condena a muerte de menores de edad ${ }^{82}$, la prohibición de la tortura ${ }^{83}$, el principio del non-refoulement ${ }^{84}$, la prohibición de cometer crímenes contra la humanidad ${ }^{85} \mathrm{o}$ la prohibición de la esclavitud o prácticas similares ${ }^{86}$.

Junto a ello, también debemos poner de relieve algunas decisiones del Tribunal Penal Internacional para la ex Yugoslavia. Entre ellas, la sentencia de 16 de noviembre de 1998, de la Sala de Primera Instancia II quater en el asunto Prosecutor v. Delacic et al., donde se señaló que la prohibición contra la tortura tenía naturaleza consuetudinaria en el Derecho internacional contemporáneo y rango de jus cogens ${ }^{87}$. Asimismo, en su Sentencia de 10 de diciembre de 1998, en el caso Prosecutor v. Anto Furundžija, la Sala de Primera Instancia II, desarrolló con más profundidad la cuestión, extrayendo además las consecuencias que tanto a nivel estatal como individual se derivaban del hecho de que la norma que prohíbe la tortura fuera una norma imperativa. Así, en opinión de la Sala, en el ámbito estatal, todo acto de naturaleza legislativa, administrativa o judicial que autorizara la tortura no sería considerado como legítimo y, en lo concerniente al plano individual, todo Estado estaría capacitado para investigar, enjuiciar y castigar o extraditar a todo individuo acusado de tortura que se encontrara en el territorio bajo su jurisdicción ${ }^{88}$. Así, en la apelación en el asunto Prosecutor v. Delacic et al., la Sala de Apelaciones también hizo notar "[...] that in human rights law the violation of rights which have reached the level of jus cogens, such as torture, may constitute international crimes ${ }^{89}$, con lo que extiende el ámbito de vigencia de las normas imperativas a la esfera de la responsabilidad internacional.

Paralelamente, el Tribunal Penal Internacional para la ex Yugoslavia ha afirmado que la prohibición de genocidio constituye también una norma de jus cogens en su Sentencia de 2 de agosto de 2001 en el asunto Krstic ${ }^{90}$.

Asimismo, en el asunto Kupreškić, el Tribunal estimó que «most norms of international humanitarian law, in particular those prohibiting war crimes,

81 Informe núm. 47/96. Caso 11.436. Víctimas del barco remolcador "13 de marzo» c. Cuba, 16 de octubre de 1996, párr. 79.

82 James Terry Roach and Jay Pinkerton v. United States, Case 9647, Res. 3/87, 22 September 1987, Annual Report of the IACHR 1986-87, párr. 56.

${ }^{83}$ Quinto informe sobre la situación de los derechos humanos en Guatemala, de 6 de abril de 2001, Documento OEA/Ser.L/V/II.111, Capítulo VI, párr. 8.

${ }^{84}$ Segundo informe de progreso de la relatoría sobre trabajadores migratorios y miembros de sus familias en el hemisferio, de 16 de abril de 2001, Informe anual de la Comisión Interamericana de Derechos Humanos 2000, Capítulo VI, párr. 97.

85 Comisión Interamericana de Derechos Humanos, Pronunciamiento de 17 de mayo de 2011, sobre el deber del Estado haitiano de investigar las graves violaciones a los derechos humanos cometidas durante el régimen de Jean-Claude Duvalier, párr. 10.

86 Comisión Interamericana de Derechos Humanos, Informe de 24 de diciembre de 2009 sobre la situación del pueblo indígena guaraní en la región del Chaco Boliviano, párr. 54.

87 Prosecutor v. Delaci and Others, Case IT-96-21-T, Judgment, 16 November 1998, párr. 454.

88 Prosecutorv. Furundžija, Case IT-95-17/1-T, Judgment, 10 December 1998, párr. 153.

89 Prosecutor v. Delaci and Others, Case IT-96-21-A, Judgment, 20 February 2001, párr. 172, nota 225 .

90 Prosecutor v. Krstic, Case IT-98-33-T, Judgment of 02 August 2001, párr. 541. 
crimes against humanity and genocide, are also peremptory norms of international law or jus cogens» ${ }^{91}$.

Por lo que concierne al Tribunal Penal Internacional para Ruanda, en su Sentencia de 21 de mayo de 1999, en el asunto Kayishema y Ruzindana, la Sala II advirtió que "the crime of genocide is considered part of international customary law and, moreover, a norm of jus cogens» ${ }^{92}$.

Quizá debería concederse, sin embargo, una especial atención por su rotundidad y alcance a cierta jurisprudencia relativamente reciente del hoy Tribunal de Justicia de la Unión Europea. Me refiero, en particular, a las decisiones adoptadas por las diversas instancias de la institución judicial comunitaria en relación con la compatibilidad de un Reglamento del Consejo de la Unión Europea que aplicaba, en el ámbito de la Unión, mediante la imposición de sanciones económicas y financieras contra determinadas personas y entidades ligadas a Osama Bin Laden, a la red Al-Qaida y a los talibanes, las sanciones impuestas por el Consejo de Seguridad de las Naciones Unidas tras los atentados que tuvieron lugar el 11 de septiembre de $2001^{93}$. En primera instancia, el Tribunal de Primera Instancia de las Comunidades Europeas, en sendas Sentencias de 21 de septiembre de $2005^{94}$, desestimó la totalidad de los motivos invocados por los recurrentes, manteniendo los efectos del Reglamento. En esas decisiones el Tribunal de Primera Instancia declaró que los tribunales comunitarios no tenían, en principio, competencia alguna para controlar la validez del Reglamento en cuestión dado que la Carta de las Naciones Unidas, tratado internacional que prima sobre el Derecho comunitario, obliga a los Estados miembros a cumplir las resoluciones del Consejo de Seguridad. Junto a ello, el Tribunal reconoció que las resoluciones del Consejo de Seguridad controvertidas no estaban sometidas, en principio, a su control jurisdiccional y que, por tanto, no se consideraba autorizado a cuestionar, ni siquiera de modo incidental, la legalidad de las mismas desde el punto de vista del Derecho comunitario ${ }^{95}$. El Tribunal estimó, por el contrario, que estaba facultado "para controlar, de modo incidental, la legalidad de las resoluciones del Consejo de Seguridad controvertidas desde el punto de vista del ius cogens» considerando a éste "como un orden público internacional que se impone a todos los sujetos del Derecho

91 Prosecutor v. Kupreškić et al., Case IT-95-16-T, Judgment, 14 January 2000, párr. 520.

92 Prosecutor v. Kayishema and Ruzindana, Case ICTR-95-1-T, Judgment, 21 May 1999, párr. 88.

93 Reglamento (CE) núm. 881/2002 del Consejo, de 27 de mayo, por el que se imponen determinadas medidas restrictivas específicas dirigidas contra determinadas personas y entidades asociadas con Usamah bin Ladin, la red Al-Qaida y los talibanes y por el que se deroga el Reglamento (CE) núm. 467/2001 (DO L 139, p. 9).

94 Sentencias de 21 de septiembre de 2005, Yusufy Al Barakaat International Foundation/Consejo y Comisión (T-306/01) y Kadi/Consejo y Comisión (T-315/01). Sobre estas sentencias véase RoLDÁN BARBERO, J., «Jurisprudencia en materia de Derecho internacional público: la justicia comunitaria y el control de legalidad de las resoluciones del Consejo de Seguridad de Naciones Unidas. Comentario a las Sentencias Yusuf/al Barakaat y Kadi, de 21 de septiembre de 2005, del Tribunal de Primera Instancia de las Comunidades Europeas», REDI, vol. LVII, 2005, núm. 2, pp. 869-891.

95 Sentencia de 21 de septiembre de 2005, Yusuf y Al Barakaat International Foundation/Consejo y Comisión (T-306/01), párr. 276. 
internacional, incluidos los órganos de la ONU, y que no tolera excepción alguna» ${ }^{96}$.

Pero aún llega más lejos el Tribunal, quien hace depender la misma obligatoriedad de las resoluciones del Consejo de Seguridad, en materia de mantenimiento de la paz y la seguridad internacionales, de su coherencia con las normas de jus cogens. En palabras del Tribunal:

«El Derecho internacional permite considerar, pues, que existe un límite al principio de la obligatoriedad de las resoluciones del Consejo de Seguridad: tales resoluciones deben respetar las normas perentorias fundamentales del ius cogens. En caso contrario, por improbable que sea dicho supuesto, no vincularían a los Estados miembros de la ONU ni, por tanto, a la Comunidad ${ }^{97}$.

Puede apreciarse, por tanto, el inmenso valor que otorgaba el Tribunal de Primera Instancia a la institución del jus cogens, que por incorporar los valores esenciales de la Comunidad internacional en su conjunto se impone incluso al propio Consejo de Seguridad. De este modo, el Tribunal de Primera Instancia consideró que su control jurisdiccional incidental podía extenderse «a la verificación de la observancia de las normas superiores del Derecho internacional que forman parte del jus cogens»y, en particular, continúa el Tribunal, «de las normas imperativas para la protección universal de los derechos humanos, que no toleran excepción alguna por parte de los Estados miembros ni de los órganos de la $\mathrm{ONU}{ }^{98}$. Sobre esas consideraciones de Derecho procedió al examen de la posible violación de los derechos fundamentales de los demandantes, llegando a la conclusión de que el reglamento impugnado no los violaba ${ }^{99}$.

Sin embargo, en segunda instancia, el Tribunal de Justicia de las Comunidades Europeas anuló las decisiones anteriores y el Reglamento en cuestión, al estimar que los tribunales comunitarios deben garantizar un control, en principio completo, de la legalidad de todos los actos comunitarios desde el punto de vista de los derechos fundamentales que forman parte integrante de los principios generales del Derecho de la Unión; comprendidos también aquellos actos comunitarios destinados a aplicar resoluciones aprobadas por el Consejo de Seguridad, como el Reglamento controvertido ${ }^{100}$. Pero en lo tocante a las normas de jus cogens, el Tribunal de Justicia no modificó las decisiones emitidas en primera instancia.

El Tribunal Europeo de Derechos Humanos también se ha venido refiriendo a las normas de jus cogens y ha señalado alguna de ellas. Así, por ejemplo, en el asunto Jorgic v. Germany, el Tribunal afirmó que la prohibición del

96 Ibid., párr. 277.

97 Ibid., párr. 281.

98 Ibid., párr. 282.

99 Ibid. párrs. 283-347.

100 Sentencia del Tribunal de Justicia (Gran Sala) de 3 de septiembre de 2008, Kadi y Al Barakaat International Foundation/Consejo y Comisión (C-402/05 P), párr. 326. Sobre esta sentencia, véase BenLOLO-CRABot, M., «La CJCE et la protection des valeurs fondamentales de l'ordre juridique communautaire», Revue du Marché commun et de l'Union européenne, 2009, núm. 529, pp. 380-386. 
genocidio ha adquirido ese rango ${ }^{101}$. Posteriormente, en el asunto Al-Adsani c. Royaume-Uni, afirmó, sobre la base de las decisiones Furundzija del Tribunal Penal Internacional para la ex Yugoslavia y Pinochet de la Cámara de los Lores británica, que la norma que prohíbe la tortura también ha alcanzado el rango de norma imperativa ${ }^{102}$.

\section{LA PRÁCTICA ESTATAL}

De entrada debemos advertir que la práctica estatal ya ha sido expuesta a los ojos del lector de forma indirecta en la medida en que se ha presentado la práctica internacional, toda vez que las instancias internacionales, al adoptar sus actos, tienen en cuenta la opinio juris de los Estados. De todas formas, en la medida de nuestras posibilidades, intentaremos exponer de forma sintética la práctica estatal que se puede conocer de forma más o menos sencilla.

Por ejemplo, en relación con la prohibición de la tortura, la propia Corte Internacional de Justicia ha puesto recientemente de manifiesto que se trataba de una norma de naturaleza consuetudinaria universal, fundamentada en una opinio iuris muy sólida, pues ha sido introducida en el Derecho interno de la casi totalidad de los Estados y los actos de tortura han sido denunciados regularmente en el seno de instancias nacionales ${ }^{103}$.

Del mismo modo, la Corte también se ha hecho eco de que numerosas jurisdicciones nacionales no han dado prioridad a las normas de jus cogens sobre las normas que reconocen las inmunidades, por situarse en planos diferentes del ordenamiento jurídico ${ }^{104}$. En sentido contrario, se constató que únicamente las decisiones de los tribunales italianos en causa, en el asunto de las Inmunidades jurisdiccionales del Estado, daban prioridad a las normas imperativas sobre aquellas que otorgan inmunidades de jurisdicción ${ }^{105}$.

En relación con los principios esenciales del Derecho humanitario, varios tribunales internos han proclamado que aquéllos han adquirido rango de jus

101 European Court of Human Rights, case of Jorgic v. Germany, Judgment, 12 July 2007, párr. 68.

102 Cour européenne des Droits de l'Homme, Affaire Al-Adsani c. Royaume-Uni, Arrêt du 21 novembre 2001, párr. 61 .

103 Questions concernant l'obligation de poursuivre ou d'extrader (Belgique c. Sénégal), arrêt, CIJ Recueil 2012, párr. 99.

104 Immunités juridictionnelles de l'Etat (Allemagne c. Italie); Grèce (intervenant), arrêt, CIJ Recueil 2012, párr. 96. En ese párrafo, la Corte cita, en concreto, las decisiones del Reino Unido [Jones c. Arabie saoudite, Chambre des lords (2007) 1 AC 270; ILR, vol. 129, p. 629], Canadá [Bouzari c. République islamique d'Iran, Cour d'appel de l'Ontario (2004) DLR, 4th Series, vol. 243, p. 406; ILR, vol. 128, p. 586], Polonia (Natoniewski, Cour suprême, Polish Yearbook of International Law, vol. XXX, 2010, p. 299), Eslovenia (arrêt de la Cour constitutionnelle en l'affaire no Up-13/99), Nueva Zelanda [Fang c. Jiang, Haute Cour (2007) NZAR, p. 420; ILR, vol. 141, p. 702] y de Grecia (Margellos, Tribunal supérieur spécial, ILR, vol. 129, p. 525).

105 Immunités juridictionnelles de l'Etat (Allemagne c. Italie); Grèce (intervenant), arrêt, CIJ Recueil 2012, párr. 96. Se trata, por ejemplo, del asunto Ferrini c. République fédérale d'Allemagne, decisión núm. 5044/2004 (Rivista di diritto internazionale, vol. 87, 2004, p. 539). 
cogens. A este respecto, podemos citar, por ejemplo, una decisión de la Corte Constitucional de Colombia, que manifestó con rotundidad que:

"[T]he essential principles of international humanitarian law have acquired ius cogens status, based on the fact that the international community as a whole has recognized their peremptory and imperative nature in the same way it has recognized this for other cardinal provisions such as [...] the prohibition of slavery» ${ }^{106}$.

Paralelamente, numerosas decisiones nacionales han declarado que los crímenes internacionales constituyen violaciones de las normas de jus cogens ${ }^{107}$.

106 Colombia Constitutional Court, Constitutional Case núm. C-291/07, Judgment, 25 April 2007, p. 70. Un tribunal alemán indicó en 2005, en el asunto Limits of Obedience to Superior Orders case, que: "Elements of "ius cogens" are, inter alia, the international law prohibition on the use of force, reflected in Article 2, núm. 4 of the UN Charter, and the fundamental rules of the humanitarian international law of war» (Federal Administrative Court, Limits of Obedience to Superior Orders case, Judgment, 21 June 2005).

Del mismo modo, un tribunal griego sostuvo, en relación con la obligación de respetar la propiedad privada por parte de la potencia ocupante, que: "[T]he occupant is obliged to respect, during the administration of the occupied land, the legislation of the latter (article 43 of the fourth Hague Convention 1907) as well as international law, including the provisions of the Regulation of Laws and Customs of War on Land, annexed to the fourth Hague Convention (19th October 1907) [...] especially the provision of article 46, according to which "[...] private property [...] must be respected". This rule is generally accepted as constituting peremptory international customary law (jus cogens)» (Greece's Court of First Instance of Leivadia, Prefecture of Voiotia case, Judgment, 30 October 1997). Por su parte, en el asunto Margellos, el Tribunal de Apelación de Atenas, en 1999, expuso que: «The generally accepted rules of international law that govern the obligations of the occupying power in relation to the administration of the occupied land are included in the Regulation of Laws and Customs of War on Land, annexed to the fourth Hague Convention (19th October 1907). Although not ratified by Greece, this Regulation constitutes international customary law (see the judgement of the International Military Tribunal for Germany) [...] The deliberate arson and damage to property, in violation of international ius cogens rules, committed by the German occupation army against Greek civilians, are of a iure gestionis nature, because these acts do not form part of the powers that can be exercised by an occupation army. The above-mentioned rule is of a ius cogens nature and its violation deprives the foreign state of the right to claim immunity" (Court of Appeal of Athens, Margellos case, Judgment of 1999).

107 A este respecto, podemos citar la decisión núm. 53/1993, del Tribunal Constitucional de Hungría, donde se señaló que: «The definition of and conditions for the punishment of war crimes and crimes against humanity are provided by international law; these crimes —directly or indirectly through the obligations assumed by the States - are prosecuted and punished by the community of nations. The regulations on the punishment of war crimes and crimes against humanity — since these crimes threaten the foundations of humanity and international coexistence- form the peremptory norms of general international law (jus cogens). Those States which refuse to assume these obligations cannot participate in the community of nations» (Hungary, Constitutional Court, Decision núm. 53/1993, 13 October 1993, Reasoning, Part. V, párr. 1).

Asimismo, podemos exponer una cita de la Corte Suprema de Argentina, en su sentencia de 1995 en el asunto Priebke, donde declaró que: «The classification of offenses as crimes against humanity does not depend on whether the requesting or requested State agrees with the extradition process, but instead on the principles of jus cogens of international law» (Argentina, Supreme Court of Justice, Priebke case, Judgment, 2 November 1995).

De la misma manera, debemos traer a colación la archiconocida decisión de 1999 de la House of Lords británica en el asunto Pinochet en la que Lord Millet advirtió que: «In my opinion, crimes prohibited by international law attract universal jurisdiction under customary international law if two criteria are satisfied. First, they must be contrary to a peremptory norm of international law so as to infringe a jus cogens. Secondly, they must be so serious and on such a scale that they can justly be regarded as an attack on the international legal order. Isolated offenses, even if committed by public officials, would not satisfy these criteria» (United Kingdom, House of Lords, Pinochet extradition case, Opinión of Lord Millett, 24 March 1999). 
En lo tocante a España, cabe recordar cómo la Sala de lo Penal de la Audiencia Nacional, afirmó en 1998, en el asunto Pinochet, que el Decreto-Ley de Chile, de Amnistía General, de 1978, no podía impedir el ejercicio de la jurisdicción universal por los tribunales españoles y que esa norma chilena podía ser considerada contraria al jus cogens internacional ${ }^{108}$.

\section{CONCLUSIONES}

Un examen de la práctica posterior a la Convención de Viena de 1969 en busca del consenso exigido expresamente en el texto del art. 53, obliga a concluir que no se ha establecido nunca ninguna norma de este tipo, ni por vía consuetudinaria ni por vía convencional; ni tampoco se ha declarado nunca un determinado tratado nulo, ni se han utilizado las otras disposiciones relativas al régimen jurídico de la nulidad de los tratados en la Convención de Viena. De hecho, en relación con el Derecho de los tratados, tan sólo se cuenta con un tratado que haya vuelto a hacer mención de las normas de jus cogens, la Convención de Viena sobre Derecho de los tratados entre Estados y organizaciones internacionales y entre organizaciones internacionales entre sí de 1986.

A la postre, flotaría en el aire la sensación de que el intento de brindar seguridad y rigor a las normas de jus cogens en la Conferencia de Viena de 1968-1969 mediante su positivación ha provocado que el régimen jurídico de las normas imperativas en el marco del Derecho de los tratados se encuentre en la actualidad en una especie de vía muerta, pues no parece probable que a corto plazo la comunidad de Estados se ponga de acuerdo para la tarea de fijar alguna de aquellas normas.

Conviene añadir que, en su sentencia de 2006, en el asunto Paunović, el Panel de Apelación del Tribunal de Bosnia-Herzegovina dijo que: "Crimes Against Humanity thus constitute an imperative principle of international law or rather jus cogens, and it is beyond dispute that in 1992 crimes against humanity were an integral part of international customary law» (Court of Bosnia and Herzegovina, Paunović case, Judgment, 26 October 2006).

En el año 2007, la Corte Suprema de Perú determinó que: «[T]he crime of enforced disappearance, just like every crime against humanity, before becoming a positive rule of criminal law already belonged to what is called "ius cogens", that is to say, it was part of common law. This is why for many scholars it was unnecessary for such crime to be incorporated into national legal frameworks. Since the crime of enforced disappearance was already part [...] of humankind, the ability to prosecute and punish such a crime is already an obligation binding every state, as has repeatedly been stated by the Inter-American Court of Human Rights in its jurisprudence» (Supreme Court of Justice, National Criminal Chamber, Chuschi case, Case núm. 104-04, Judgment, 5 February 2007).

Por último, cabe citar una decisión de la Corte de Apelaciones de Santiago de Chile, que hizo notar recientemente que: "[T]he prohibition of criminal action under domestic law with respect to crimes against humanity is null and void because the non-applicability of statutory limitations to crimes against humanity is an imperative norm of general international law, which has [...] been incorporated into constitutional law by way of an international treaties and [prior to this incorporation] was binding as a general principle of international human rights law» (Court of Appeal of Santiago, Fifth Chamber, María Barros Perelman case, Case núm. 24.471-2005, Judgment, 5 September 2009).

108 Una copia del Auto de 4 de noviembre de 1998 de la Audiencia Nacional se puede encontrar, junto a un comentario de la misma, en REDI, vol. LI, 1999, núm. 2, pp. 642-656. Sobre esta decisión véase, entre otros trabajos, Márouez Carrasco, M. C. y Alcaide Fernández, J., "In Re Pinochet et al.», AJIL, vol. 93, 1999, pp. 690-696. 
A pesar de ello, se debe tener presente que, en alguna ocasión, los silencios son más elocuentes que las palabras y las ausencias más significativas que las presencias. En esta línea entendemos que la ausencia de positivación posterior a la Convención de Viena de 1969 no es completamente estéril en cuanto a su significado, pues el que se haya consolidado la noción de jus cogens en la realidad - como hemos visto a lo largo de este trabajo- sin que se haya nunca positivado ninguna norma imperativa demuestra que, en relación con la institución del jus cogens, el elemento espiritual o valorativo es más importante que el técnico jurídico o positivo. Es decir, que los Estados están de acuerdo en reconocer que existen determinadas normas que deben quedar por encima de la voluntad de ellos mismos por acoger los valores superiores de la comunidad internacional y que deben ser protegidas; aunque no se hayan todavía puesto de acuerdo en cómo determinar cuáles son esas normas y, mucho menos, haberlo efectuado ${ }^{109}$.

Por otra parte, dejando de lado la ausencia de determinación por los Estados de las normas imperativas, si se observan otros parámetros de la práctica subsiguiente a la adopción de la Convención de Viena de 1969 se pueden llegar a otras conclusiones muy significativas.

Así, se constata, en primer lugar, que, al menos, la noción de jus cogens se ha ido consolidando. Ha sido empleada, definida y aplicada por numerosos órganos y organismos tanto de las Naciones Unidas como de organizaciones internacionales regionales. Destaca el amplio uso de esta categoría que han ido poco a poco haciendo las diferentes jurisdicciones internacionales, también en los últimos tiempos la Corte Internacional de Justicia. De tal manera que, como lo ha reconocido la propia CDI, «[e]l concepto de norma imperativa de Derecho internacional general se reconoce en la práctica internacional, en la jurisprudencia de las cortes y tribunales internacionales y nacionales y en la doctrina jurídica» ${ }^{110}$. Buena prueba de ello viene constituida por el hecho de que, jsorpréndanse!, el gran antagonista de la noción, el Estado francés, haya terminado por aceptarla ${ }^{111}$.

109 Como lo advierte Bruno Simma, «It is also well-known that the articles embodied in the 1969 Convention limit themselves to a consensual concept that does not go to the heart of the matter because a substantive definition of ius cogens would have been too closely connected to natural law philosophy to be universally acceptable. However, the conception of ius cogens will remain incomplete as long as it is not based on a philosophy of values like natural law. In this regard, what Verdross's ideas offer is a natural link between the ius cogens rules now codified and one possible philosophical foundation". Véase SImmA, B., "The Contribution of Alfred Verdross to the Theory of International Law», EJIL, vol. 6,1995 , p. 53.

110 Véase el comentario al art. 40 del proyecto de artículos de la CDI sobre Responsabilidad Internacional de los Estados, Informe de la Comisión de Derecho Internacional - 53. ${ }^{\circ}$ periodo de sesiones (23 de abril a 1 de junio y 2 de julio a 10 de agosto de 2001), Asamblea General, Documentos Oficiales, 56. ${ }^{\circ}$ periodo de sesiones, Suplemento núm. 10 (A/56/10), p. 305.

111 Como lo ha manifestado recientemente el Profesor Pellet en relación con Francia, "la guéguerre" qu'elle a trop longtemps livrée à la notion de normes impératives est terminée; et si, par exemple, vous lisez attentivement les interventions du Conseiller juridique du Quai d'Orsay à la Sixième Commission de l'Assemblée générale depuis quatre ou cinq ans, vous constaterez que l'expression jus cogens ne lui brûle plus la langue». Véase Pellet, A., «Conclusions», en Tomuschat, C. y Thouvenin, J. M. (eds.), op. cit., nota 27, p. 419. 
Por ello, a la postre, quizá se cuente ya con base suficiente para concluir que la noción de jus cogens contenida en la CVDT se ha transformado en una norma de Derecho internacional general ${ }^{112}$.

Por otro lado, en segundo lugar, la práctica de la Asamblea General y del Consejo de Seguridad de las Naciones Unidas apunta también a que los efectos jurídicos de la noción de jus cogens se han extendido fuera del ámbito estrictamente del Derecho de los tratados, impregnando todo el ámbito de las fuentes normativas en el Derecho internacional. Así, se debe entender que no sólo los tratados serán nulos por oponerse a una norma imperativa, sino que todo acto o norma que sea contrario a las normas de jus cogens también debería verse abocado a la nulidad.

La CDI allana también el camino en esa dirección al haber previsto, en sus Principios rectores aplicables a las declaraciones unilaterales de los Estados capaces de crear obligaciones jurídicas, que toda declaración unilateral que esté en oposición con una norma imperativa de Derecho internacional general será nula.

La influencia del jus cogens se deja también notar, en tercer lugar, en el ámbito de la subjetividad internacional, pues como la Convención de Viena sobre Derecho de los tratados de 1986 entre Estados y organizaciones internacionales y entre organizaciones internacionales entre sí lo demuestra, tampoco las organizaciones internacionales pueden adoptar tratados contrarios a las normas imperativas. Esta percepción ha quedado también reforzada por algún otro dato de la práctica internacional. Nos referimos, por ejemplo, a alguna decisión de los tribunales que integran la institución judicial de la Unión Europea, cuando señalaron que el propio Consejo de Seguridad de las Naciones Unidas también debe atenerse a las normas imperativas en su actividad en el marco del capítulo VII de la Carta de las Naciones Unidas. Paralelamente, y sin ánimo de ser exhaustivos, podemos referir el proyecto de artículos de la CDI sobre responsabilidad internacional de las organizaciones internacionales, que, como va dicho, contiene varias referencias a las normas de jus cogens, con lo que resulta evidente que éstas también deben ser respetadas por estos nuevos sujetos del Derecho internacional y su violación acarrearía consecuencias en el plano de la responsabilidad.

Junto a ello, en cuarto lugar, la práctica internacional testimonia que numerosas instancias internacionales, en particular las diversas jurisdicciones internacionales, incluida la Corte Internacional de Justicia, y numerosas jurisdicciones nacionales, además de utilizar la noción de normas imperativas o jus cogens, van afirmando de modo creciente que algunas normas ya han adquirido ese rango en el ordenamiento jurídico contemporáneo ${ }^{113}$. Es

112 En esta línea, véase, por ejemplo, Gutiérrez EsPADA, C., «Sobre las normas imperativas del Derecho internacional», en Pacis artes: obra homenaje al profesor Julio D. González Campos, vol. I, Madrid, Eurolex, 2005, p. 273.

113 De la consolidación de la noción de jus cogens se pueden asimismo, legítimamente, extraer consecuencias acerca de la existencia de una jerarquía normativa en el ordenamiento jurídico interna- 
el caso, sobre todo, de la prohibición de la tortura, pero también de la prohibición de genocidio, de la prohibición de la esclavitud, de otras normas esenciales del Derecho humanitario, etc. Como corolario, se deduce que la institución de las normas imperativas comienza también a impregnar el ámbito de la responsabilidad internacional, como también ha previsto la CDI en sus proyectos sobre responsabilidad internacional, tanto de los Estados como de las organizaciones internacionales.

No obstante, por el momento, la práctica internacional no permite afirmar una influencia decisiva de la existencia de las normas imperativas en otros ámbitos, como el de la competencia de los tribunales nacionales e internacionales. En efecto, la jurisprudencia de los tribunales nacionales e internacionales, y también de la Corte Internacional de Justicia, va en la línea de considerar que el hecho de que en el fondo de los asuntos se dirima la posible violación de normas de jus cogens no otorga competencia al tribunal de que se trate, en el sentido de excepcionar la regla de la necesidad de contar con el consentimiento de las partes en el asunto o de hacer perder su eficacia a las inmunidades jurisdiccionales reconocidas por el Derecho internacional a los Estados o a sus altos cargos ${ }^{114}$.

En definitiva, a la pregunta que nos hicimos en la introducción, basándonos en una afirmación del Profesor Brownlie, sobre si el jus cogens es un vehículo que ha salido poco del garaje, debemos acabar constatando que el jus cogens ha empezado a salir del garaje, y aunque no se haya movido todavía mucho, va extendiendo su radio de acción en su propio barrio (el Derecho de los tratados y el de las otras fuentes jurídicas) y comienza ya a dejarse ver en otros barrios del ordenamiento jurídico internacional, como el de la subjetividad internacional o el de la responsabilidad internacional.

\section{RESUMEN}

\section{EL JUS COGENS, ¿SALIÓ DEL GARAJE?}

Durante la preparación de la CVDT de 1969, la CDI advirtió, en relación con la definición del jus cogens, que habría que limitarse en ese momento a establecer en términos generales que un tratado sería nulo si entrara en conflicto con tales normas y dejar que la práctica estatal y la jurisprudencia de los tribunales internacionales determinara el contenido completo de esa regla. Transcurridos más de cuarenta años desde la adopción de la Convención, la práctica nos brinda ya perspectiva suficiente para poder realizar ese ejercicio con garantías. Comprobamos como la noción jus cogens se ha consolidado definitiva-

cional, de que la voluntad de los Estados no es la regla absoluta a la hora de la producción normativa y de que hay determinados principios que actúan como límites a la actuación de los sujetos en el ordenamiento jurídico internacional. Todo ello delinea en el horizonte una cierta madurez de la sociedad internacional que ha sabido proclamar unos valores y procurado defenderlos a través de una serie de mecanismos jurídicos; por muy imperfectos que éstos fueren.

114 Sobre un comentario a la sentencia de la Corte Internacional de Justicia en el asunto inmunidades del Estado, desde el punto de vista de la relación jus cogens/inmunidades, véase CEBADA RoMERO, A., «El Derecho internacional global: una retórica útil para una transformación necesaria», REDI, vol. LXV, 2013, núm. 1, pp. 34-38. 
mente. Además, aunque la comunidad internacional no haya señalado todavía algunas de esas normas, las instancias internacionales lo van haciendo de forma creciente. Asimismo, los efectos jurídicos de esta institución se hacen notar fuera del ámbito estrictamente del Derecho de los tratados, impregnando todo el terreno de las fuentes normativas, y poco a poco también los de la subjetividad y la responsabilidad internacionales.

Palabras clave: Jus cogens, fuentes del Derecho internacional, responsabilidad internacional, subjetividad internacional, competencia de los tribunales internacionales y nacionales.

\section{ABSTRACT \\ JUS COGENS: DID IT LEAVE THE GARAGE?}

During the preparation of the VCLT, the ILC considered that «the right course [was] to provide in general terms that a treaty is void if it conflicts with a rule of jus cogens and to leave the full content of this rule to be worked out in State practice and in the jurisprudence of international tribunals». Now, more than forty years since the adoption of the Convention, practical experience has provided us with sufficient perspective to be able to apply the concept of jus cogens reliably and effectively. Indeed, the concept has become definitively consolidated. Besides, even though the international community has not yet recognized some of its rules, international institutions are increasingly doing so. Likewise, the legal effects of jus cogens are becoming established outside the strict framework of the law of treaties, impregnating the whole area of the sources of law and, gradually, the areas of both international subjectivity and international responsibility as well.

Keywords: Jus cogens, sources of International Law, international responsibility, international subjectivity, competence of international and municipal tribunals.

\section{RÉSUMÉ}

\section{LE JUS COGENS, EST-IL SORTI DU GARAGE?}

Lors des travaux préparatoires de la CVDT de 1969, la CDI a jugé, en ce qui concerne la définition du jus cogens, que la bonne solution consistait à stipuler en termes généraux qu'un traité est nul s'il est incompatible avec une règle de jus cogens et d'attendre que la pratique des États et la jurisprudence des tribunaux internationaux mettent au point la pleine teneur de cette règle. Plus de quarante ans étant passés depuis l'adoption de la Convention, la pratique nous permet maintenant d'y procéder en ayant un recul suffisant. Tout d'abord, on a constaté que la notion du jus cogens s'est définitivement consolidée. Par ailleurs, bien que la communauté internationale n'ait encore signalé que quelques-unes de ces normes, les instances internationales le font de plus en plus. Il est possible également de repérer des effets juridiques du jus cogens en dehors du Droit des traités, comme par exemple dans tout l'éventail des sources du Droit international ainsi que, petit à petit, dans le cadre de la subjectivité internationale ou celui de la responsabilité internationale.

Mots-clés: Jus cogens, sources du Droit international, responsabilité internationale, subjectivité internationale, compétence des tribunaux internationaux et des tribunaux nationaux. 